\title{
Quantitative Analysis of VOCs in Exhaled Breath from Asian Volunteers: A Pilot Study
}

Shruti Pavagadhi and Rajasekhar Balasubramanian *

Department of Civil and Environmental Engineering, National University of Singapore, Singapore

"Corresponding author: Rajasekhar Balasubramanian, Department of Civil and Environmental Engineering, 1 Engineering Drive 2, E1A 07-03, National University of Singapore, Singapore 117576, Tel: 656516 6666; E-mail: ceerbala@nus.edu.sg

Rec date: Oct 20, 2014; Acc date: Oct 31, 2014; Pub date: Nov 03, 2014

Copyright: (C) 2014 Pavagadhi S, et al. This is an open-access article distributed under the terms of the Creative Commons Attribution License, which permits unrestricted use, distribution, and reproduction in any medium, provided the original author and source are credited.

\begin{abstract}
Background: High incidences of respiratory ailments have been long attributed to rapid industrialization and fast economic growth in developing nations within Asia. Urbanization in particular has led to a significant increase in outdoor and indoor air pollution in Asian countries, affecting lung health for different population groups. Air pollutants enter the human systems via the inhalation pathway, and their measurement in exhaled breath has been suggested as a non-invasive alternative for early diagnosis of asthma and lung cancer. Routine monitoring of selected volatile organic compounds (VOCs) in breath often requires the use of robust analytical techniques with standardized sample collection procedures for reliable risk assessment. Currently, such analytical data are relatively sparse in the literature for Asian population groups due to lack of quantitative analysis of VOCs in exhaled breath. To fill the knowledge gap, a present pilot study was initiated to evaluate the suitability of an in situ instrumental technique for breath measurements among a small group of diverse Asian volunteers.
\end{abstract}

Methods: The study was conducted to explore the use of PTR-MS (Proton Transfer Reaction- Mass Spectrometry) with BET (Buffered End Tidal) breath sampling for real-time measurements of selected VOCs in healthy Asian volunteers ( 35 healthy subjects from different ethnic groups). Breath samples were analyzed for eight VOCs (well-known biomarkers) using BET-PTRMS, namely, acetone, isoprene, ethanol, acetaldehyde, acetonitrile, acrolein, benzene and toluene. The eight VOCs were confirmed independently using a complementary analytical technique (SPME-GCMS (Solid Phase Micro-Extraction-Gas Chromatography Mass Spectrometry)).

Results: Acetone (58\% abundance) was found to be the predominant VOC, followed by isoprene (27\%) and acetaldehyde (9\%) in the breath samples of 35 healthy Asian healthy volunteers from diverse ethnic groups. Results obtained from the present study have been compared to those available in literature for different population groups.

Conclusion: Overall, BET-PTRMS is a promising real-time monitoring tool for measurements of suitable VOCs that can be used as breath signatures ("smell prints") in Asian population groups as it demonstrated a high sensitivity and versatility required for successful practical applications. Further in-depth investigations with more number of subjects under clinical and sub-clinical settings are warranted to evaluate the potential of using BETPTRMS as a routine early diagnostic tool for Asian population groups at-risk of developing COPD, lung cancer or serious respiratory illnesses.

Keywords: PTRMS; Breath; VOCs; COPD; Air pollutants; Lung cancer

\section{Background}

Rapid urbanization together with fast economic growth in Asian sub-continents has emerged as a serious threat to public health [1]. Asia has 17 out of 29 megacities (with urban population $\geq 10$ million), and accounts for about $59 \%$ of global population according to the latest UN reports [2,3]. There have been higher incidences of respiratory ailments including asthma, COPD (chronic obstructive pulmonary disease) and lung cancer as a result of land-use changes and industrialization and their effects on the quality of both ambient and indoor air in Asian countries [4,5]. Most of the commonly found air contaminants enter the human systems via the inhalation pathway, diffuse across the blood-air barrier at the alveoli of lungs and get biodistributed among different organs [6]. Among air contaminants, volatile organic compounds (VOCs) are particularly of concern as they are ubiquitous and of both endogenous (produced within the human body) and exogenous (derived from outdoor and indoor sources) origins. In recent years, measurement of VOCs in exhaled breath has received considerable interest as it can reveal unique patterns among different individuals in a cohort with the relative abundance of specific organic compounds and thus serve as biomarkers for an early diagnosis of diseases such as lung cancer [7-9].

In view of the high prevalence of both outdoor and indoor air pollution in Asian megacities resulting from several socio-economic and cultural factors, it is of utmost importance to quantify the burden of VOCs in exhaled breath. Human breath contains hundreds of VOCs in ppb (parts per billion (by volume)) levels that are associated with normal metabolism (e.g., ethanol, isoprene, propanone, and methanol), products of oxidative stress (e.g., propanedial and pentane), and with environmental and occupational exposures (e.g., trichloromethane and benzene) [7-10]. Measurements of specific VOCs of interest in exhaled breath would help in the development of 
health risk management strategies, leading to effective pollution prevention and early diagnosis for respiratory illnesses ensuring optimum lung health for Asian populations. Moreover, sampling exhaled breath is less invasive than drawing human blood, and is also much more convenient than collecting urine samples. In addition, exhaled breath analysis can be done rapidly with fast turnaround time and minimal biohazard waste [11]. However, VOCs differ in their physico-chemical characteristics, and thus pose sampling and analytical challenges for routine breath analysis at a wide network of monitoring sites where outdoor/indoor or occupational exposures are of concern [12].

In recent years, direct injection mass spectrometry has been identified as a method of choice for real-time detection of VOCs in exhaled breath $[13,14]$. Direct injection is particularly advantageous over other analytical methods that require sample pre-treatment which may result in sample losses and false estimations of VOC concentrations [15]. The immediate availability of analytical results following the sampling of exhaled breath with low risks of artefacts and no pre-treatment requirements makes the direct injection method suitable for routine monitoring of exhaled human breath for outdoor/ indoor and occupational exposures [16]. PTR-MS (Proton Transfer Reaction-Mass Spectrometry), characterized by very low detection limits and by a soft chemical ionization often producing the molecular ion only [13], has become very popular in recent years as an analytical technique for a wide range of applications $[17,18]$. Recent research reports by King et al., on PTRMS highlights the versatility of this online analytical technique for measurement of crucial VOCs in human volunteers under various conditions $[10,17,18]$.

This preliminary study was undertaken to evaluate the suitability of PTR-MS as an on-line technique for exhaled breath monitoring of VOCs in Asian volunteers. Breath profiling data for Asian volunteers from countries with high population densities are currently sparse in the literature which makes it imperative to conduct thorough investigations with the use of standardized and robust analytical techniques.

In the present study, VOCs monitored through PTR-MS equipped with Buffered End Tidal (BET) [19] sampler were also identified using a conventional SPME-GCMS approach to validate the results. This pilot study was conducted in Southeast Asia (SEA) for the first time. Apart from the urban air pollution, the air quality of SEA is frequently adversely affected by transboundary smoke haze pollution problems, caused by uncontrolled forest and peat fires in Indonesia, apart from local urban emissions of air pollutants [20]. In recent years, there has been a surge in the number of asthma cases and in the occurrence of respiratory ailments and lung cancers among non-smokers in SEA [21]. Therefore, there is an urgent need to evaluate and establish reliable analytical protocols for in situ monitoring of VOCs in exhaled breath of different ethnic groups of Asian volunteers, prior to clinical trials.

\section{Methods}

\section{Human subjects}

A cohort of 35 healthy Asian subjects (average age: 30, age range: 24-36, 22 males, 13 females) were recruited; a narrow age range for the study group was a result of the exclusion criteria used to select 'healthy' subjects. Healthy subjects (non-smokers) with no history of known lung diseases and any kind of symptoms were selected for this study. Subjects suffering from common flu, colds and any kind of throat infections and inflammations were excluded from participation in the study. The study protocol was approved by the Ethical Committee of the Institutional Review Board (IRB), National University of Singapore (NUS). All participants were informed about the study through a participant information sheet. Interested participants signed the informed consent before the enrolment in the study. All the recruited subjects were from the NUS premises, with varied occupational and workplace settings. The principal characteristics of the subjects and their nature of work are reported in Table 1. Breath sampling was carried out in the morning from fasting subjects. Subjects were also asked to refrain, since the evening before the measurement, from using mouthwash, drinking alcohol and consuming heavily flavored meals.

\begin{tabular}{|l|l|l|l|}
\hline $\begin{array}{l}\text { Subjects } \\
\text { (Race) }\end{array}$ & Male/Female & Age Range & $\begin{array}{l}\text { Occupation/nature of } \\
\text { work }\end{array}$ \\
\hline Indian & $12 / 7$ & $\begin{array}{l}\text { Males: 24-36 } \\
\text { Females: } 25-29\end{array}$ & $\begin{array}{l}\text { Research activities (lab } \\
\text { work); desk job (office } \\
\text { work) }\end{array}$ \\
\hline Malaysian & $3 / 2$ & $\begin{array}{l}\text { Males: 24-26 } \\
\text { Females: 24-26 }\end{array}$ & Desk job (office work) \\
\hline Chinese & $4 / 1$ & $\begin{array}{l}\text { Males: 23-29 } \\
\text { Female: } 24\end{array}$ & $\begin{array}{l}\text { Student related activities } \\
\text { (attending lectures); } \\
\text { Research activities (lab } \\
\text { work) }\end{array}$ \\
\hline Singaporean & $3 / 3$ & $\begin{array}{l}\text { Male: 28-32 } \\
\text { Female: 24-28 }\end{array}$ & $\begin{array}{l}\text { Research related activities } \\
\text { (lab work) }\end{array}$ \\
\hline
\end{tabular}

Table 1: Demographic and occupational summary of the subjects involved in the study

\section{Instrumental set-up}

The PTR-MS instrument (Type: Compact PTR-MS) used for monitoring and anlyzing VOCs in breath samples was obtained from IoniconAnalytik $\mathrm{GmbH}$, Innsbruck, Austria [13]. Ionization source for PTR-MS was $\mathrm{H}_{3} \mathrm{O}^{+}$ions, which were produced from a pure water vapor flow of $7.5 \mathrm{sccm}$ (standard cubic centimetre per minute) in a hollow cathode discharge ion source. The breath sample was introduced into the drift tube with the PTR-MS at a flow rate of approximately $22 \mathrm{sccm}$, and the drift tube pressure ( $\mathrm{P}$ drift) was held at 2.2 mbar. The temperature of the sampling inlet ( $\mathrm{T}$ inlet) and the drift tube ( $\mathrm{T}$ drift) was held at $80^{\circ} \mathrm{C}$. The drift tube $(9.2 \mathrm{~cm}$ long) consisted of stainless steel ring electrodes, separated by Teflon rings for electrical isolation. The ring electrodes were connected to 25 a resistor network, which divided the overall drift voltage ( $\mathrm{U}$ drift) into a homogeneously increasing voltage and established a homogeneous electric field inside the drift tube to avoid the formation of substantial amounts of hydrated hydronium ions, $\mathrm{H}_{3} \mathrm{O}^{+} \bullet\left(\mathrm{H}_{2} \mathrm{O}\right) \mathrm{n}(\mathrm{n}=1,2, \ldots)$. In the drift tube, trace gases such as VOCs in the sample air were ionized by proton transfer reactions [13]:

\section{$\mathrm{H}_{3} \mathrm{O}^{+}+\mathrm{VOC} \rightarrow \mathrm{VOC} \cdot \mathrm{H}^{+}+\mathrm{H}_{2} \mathrm{O}$}

A fraction of these reagent ions $\left(\mathrm{H}_{3} \mathrm{O}^{+}\right)$and product ions $(\mathrm{VOC} \cdot \mathrm{H}$ ${ }^{+}$) was extracted through a small orifice into a quadrupole mass spectrometer. The ions were then detected by a secondary electron multiplier for ion pulse counting. The mass dependence of the transmission efficiency of the quadrupole mass spectrometer was calibrated by IonimedAnalytik $\mathrm{GmbH}$ using a Gas Calibration Unit 
(GCU) and a gas standard containing the compounds of interest $[22,23]$. The field strength, $\mathrm{E} / \mathrm{N}$, of the drift tube, where $\mathrm{E}$ is the electric field strength $\left(\mathrm{V} \mathrm{cm}{ }^{-1}\right)$ and $\mathrm{N}$ is the buffer gas number density (molecule $\mathrm{cm}^{-3}$ ), were set to $\mathrm{E} / \mathrm{N}=144 \mathrm{Td}$ as a trade of between pronounced cluster formation on the one hand and to minimize fragmentation of the detected VOCs on the other.

\section{Breath sampling}

The PTR-MS instrument was housed in a room on the ground floor connected to a BET on-line sampler. Human subjects were made to sit in front of the interface and asked to breathe normally. After a short period of time, the subjects were asked to exhale into a disposable mouthpiece, provided with a sputum trap, connected to the BET system. Following a normal exhalation, the initial breath stages (the dead-space) are quickly blown through the buffer tube of BET sampler. At the end of an exhalation the flow reaches zero and the last $40 \mathrm{ml}$ of the exhaled breath gas-the end-tidal fraction-remains buffered in the sampler. In this way, the BET system allows the collection of the last $40 \mathrm{ml}$ of exhaled breath gas known as end-tidal fraction. This fraction is known to be the richest in those molecules derived from exchange at the alveolar-capillary membrane the fraction of exhaled gas collected through the BET system is drawn directly to the drift tube of the PTR- MS used as an on-line detection and recording system for the VOCs spectra.

\section{Breath analysis and method optimization}

A total of eight VOCs were monitored in the breath samples of all the subjects; VOCs were selected based on their frequency of occurrence as described in the literature and their origin as discussed elsewhere in the paper. The VOCs were monitored in the breath samples of volunteers using a standardized set of conditions used for breath measurements. Standard gas mixtures were introduced at a mixing ratio of $10.5 \mathrm{ppb}$ into the PTR-MS instrument twice daily before and after taking measurements. The instrument was calibrated using a calibration gas mixture and a gas calibration unit (GCU, IonimedAnalytik, Innsbruck, Austria) [22], for each of the VOCs at their listed protonated $\mathrm{m} / \mathrm{z}$. From the calibration curve, the effective $\mathrm{k}$ rate for that VOC and the sensitivity in ncps/ppb has been calculated. A list of VOCs with their reaction rate constants (k-rates) are listed in Table 2. All the measurements were taken in triplicate with the mean and corresponding standard deviation values being reported.

From a background measurement for each VOC, the limit of detection (LOD) has been calculated as 3 times the background noise level. Repeated measurements of the standard gas mixture were done to determine LOD, relative standard deviation (RSD), accuracy and sensitivity of the measurements. No significant fragmentation of the compounds in the standard gas mixture was observed within the measured spectra. For measurements of each sample of standard gas mixture, repeated scans were made. The average of these repeated scans in counts per second (cps) was considered for concentration calculation, LOD, sensitivity, etc. (Table S1, supplementary section).

\section{Effect of ambient air on VOCs concentrations}

Concentrations of VOCs in background air (outdoor/indoor air) were also evaluated through PTR-MS and measurements thresholds for VOCs in breath samples were adjusted accordingly. This was done to eliminate the effect of surrounding air on variability and concentrations of breath gas volatiles. Before every breath gas measurement, room air samples $(n=5)$ were monitored for the presence and concentrations of VOCs (studied in the present study) to avoid over-estimations of breath gas volatiles in breath samples of volunteers.

\begin{tabular}{|l|l|l|}
\hline $\mathbf{m} / \mathbf{z}$ & Compound & k-rate \\
\hline 42 & Acetonitrile & 3.56 \\
\hline 45 & Acetaldehyde & 3.27 \\
\hline 47 & Ethanol & 0.12 \\
\hline 57 & Acrolein & 2.5 \\
\hline 59 & Aceton & 3.44 \\
\hline 69 & Isoprene & 0.85 \\
\hline 79 & Benzene & 1.96 \\
\hline 93 & Toluene & 2.18 \\
\hline
\end{tabular}

Table 2: Calibrated reaction rate constants for targeted VOCs

\section{Identification of VOCs}

Identification of selected eight VOCs in breath samples was done using SPME-GCMS (Solid Phase Microextraction-Gas Chromatography Mass Spectrometry). GCMS coupled with SPME (as a preconcentration method) is defined as the gold standard among all other analytical techniques used for routine breath analyses [23-27]. For GCMS analyses, breath samples from healthy volunteers were collected in 1-1 Tedlar gas bags (SKC, USA). Subjects were asked to fast overnight (samples for BET-PTRMS and SPME-GCMS were collected on the same day), and to breathe normally in Tedlar gas bags which trapped $1 \mathrm{~L}$ breath gas through a disposable mouth piece. The VOCs trapped in the breath samples were extracted using SPME. The SPME manual holder and the fiber coated with $75 \mu \mathrm{m}$ carboxenpolydimethyl siloxane (CAR-PDMS) (Supelco USA) were used for the extraction of VOCs from breath samples [24]. The SPME fiber was pre-treated in the injection port of GC at 300SPME fiber was then inserted into Tedlar bag for $30 \mathrm{~min}$ at room temperature for extraction [24]. VOCs were desorbed thermally and analyzed after extraction. The carrier gas was helium with an air flow rate of $1 \mathrm{~mL} /$ min. A splitless injection mode was used. The gas chromatographic analyses were performed using an Agilent Technologies (USA) type 7890 gas chromatograph equipped with a mass selective detector (MSD) (type 5975C, Agilent, USA). The GC injection port temperature was $250^{\circ} \mathrm{C}$.The ion source temperature of mass spectrometer was $200 \mathrm{C}$. The data acquired were analyzed by NIST 05 library. Pure calibration mixtures of reference compounds were prepared to determine the retention time and mass spectra with respect to our analytical setting.

\section{Statistical analyses}

All the VOCs concentrations obtained from BET-PTRMS are reported as mean \pm standard deviation (S.D.). Measurements were taken in triplicates. The analytical data were analyzed using one-way ANOVA at $95 \%$ confidence limits $(\mathrm{p}<0.05)$. 


\section{Results and Discussion}

Many VOCs are reported to be prevalent in human breath [25], among which eight VOCs were selected and monitored real-time with BET-PTRMS in breath samples of 35 healthy volunteers (refer to supplementary Figure S1). These eight VOCs in breath samples were identified using the conventional SPME-GCMS approach [26].

\begin{tabular}{|c|c|c|}
\hline $\begin{array}{l}\text { Significant VOCs } \\
\text { in breath }\end{array}$ & Sources & References \\
\hline Acetone & $\begin{array}{l}\text { Glucose metabolism in the } \\
\text { human body }\end{array}$ & {$[48]$} \\
\hline Isoprene & $\begin{array}{l}\text { Mevalonic acid pathway of } \\
\text { cholesterol synthesis }\end{array}$ & {$[32]$} \\
\hline Acrolein & $\begin{array}{l}\text { Exogenous: cooked foods, } \\
\text { formed from carbohydrates, } \\
\text { vegetable oils and animal fats, } \\
\text { amino acids during heating of } \\
\text { foods, occupational exposure } \\
\text { Endogenous: myeloperoxidase- } \\
\text { mediated degradation of } \\
\text { threonine and amine oxidase- } \\
\text { mediated degradation of } \\
\text { spermine and spermidine } \\
\text { (markers for oxidative stress) }\end{array}$ & [49] \\
\hline Ethanol & 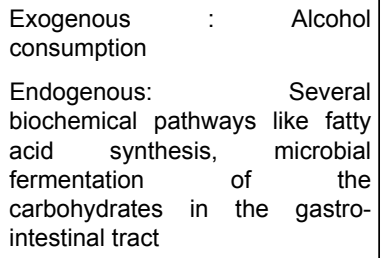 & {$[50]$} \\
\hline Acetonitrile & $\begin{array}{l}\text { Exogenous: Smokers, drug } \\
\text { addicts, passive smokers } \\
\text { Cut-off for active smokers } \\
\text { established at } 20.3 \mathrm{ppb} \text { (study } \\
\text { based on PTRMS) }\end{array}$ & {$[51]$} \\
\hline Acetaldehyde & $\begin{array}{l}\text { Endogenous: Local production in } \\
\text { upper airway or mouth; } \\
\text { metabolism of ethanol }\end{array}$ & {$[36]$} \\
\hline Benzene & $\begin{array}{l}\text { Exogenous : Passive smoking, } \\
\text { occupational }\end{array}$ & {$[37]$} \\
\hline Toluene & Exogenous: Occupational, indoor & {$[52]$} \\
\hline
\end{tabular}

Table 3: VOCs monitored through BET-PTRMS in the present study

Results showed the presence of the eight VOCs in the breath samples (representative GCMS chromatogram overlay, Supplementary Figure S2). GCMS, assisted by the SPME pre-treatment, has been successfully used by researchers for identifying VOCs in breath samples. SPME is regarded as one of the most reliable sample preparation techniques $[27,28]$. Since SPME-GCMS has been used widely in breath research for identification and detection of VOCs, it was used in the present study for confirmation of the VOCs in the breath samples. The eight VOCs monitored, namely, acetone $\left(\mathrm{C}_{3} \mathrm{H}_{6} \mathrm{O}\right)$, isoprene $\left(\mathrm{C}_{5} \mathrm{H}_{8}\right)$, acrolein $\left(\mathrm{C}_{3} \mathrm{H}_{4} \mathrm{O}\right)$, ethanol $\left(\mathrm{C}_{2} \mathrm{H}_{6} \mathrm{O}\right)$, acetonitrile $\left(\mathrm{C}_{2} \mathrm{H}_{3} \mathrm{~N}\right)$, acetaldehyde $\left(\mathrm{C}_{2} \mathrm{H}_{4} \mathrm{O}\right)$, benzene $\left(\mathrm{C}_{6} \mathrm{H}_{6}\right)$ and toluene $\left(\mathrm{C}_{7} \mathrm{H}_{8}\right)$ were selected based on (1) their frequency of occurrence as reported through several investigational studies in other continents $[29,30]$ and (2) their origin (Table 3); two out of eight
VOCs (acetone, isoprene) are endogenous compounds i.e. they are synthesized through several biochemical pathways occurring in the human body; three of them (toluene, benzene and acrolein) are purely exogenous in nature i.e., acquired in the human breath through a series of occupational and indoor/outdoor exposures; the other three of them (acetaldehyde, ethanol and acetonitrile) occur predominantly in the human breath as an influence of socio-cultural factors for example, (passive) smoking and alcohol consumption. These eight VOCs were monitored and calibrated for the Asian population groups in the present study.

From the results (Figure 1 and Table 4), it can be observed that acetone (58\% relative abundance) had the highest average concentration in subjects involved in the present study, followed by isoprene (27\%), acetaldehyde (9\%) and ethanol (4\%). Benzene and toluene were found in very low concentrations in the breath samples of the subjects. Although acetone was observed to be the VOC with the highest concentration across the groups, there were variations among the different ethnic groups. The observed variations could be due to the endogenous nature and its origin which is highly dependent on glucose metabolism in the body (Table 3 ).

Chinese subjects (350.5 ppb) had the highest concentration of acetone in their breath while the Indian subjects $(165.5 \mathrm{ppb})$ recruited under the study had the lowest concentration. It was observed that the breath acetone concentrations of Singaporean subjects (324.6 ppb) were very similar to those of the Chinese subjects. The Singaporean subjects recruited in the present study are native Chinese, which could explain the similarity patterns observed among the same ethnic group. The second dominant compound, isoprene, on the other hand, did not show much variation among different ethnic groups, and the measured concentration was in the range of $121.2-128.8 \mathrm{ppb}$. Acetaldehyde also showed a similar behavior with respect to its concentrations across the population groups studied without major variations. Interestingly, acetonitrile (10.8 ppb) concentrations showed more than 2 fold changes for breath samples of Indian subjects as compared to Chinese, Singaporean and Malaysian subjects. The concentration of acrolein was also found to be slightly higher in breath samples of Indian subjects as compared to other 3 ethnic groups in the study. On the other hand, concentrations of benzene and toluene (markers for environmental exposure/occupational exposure) were very similar for all the ethnic groups under study. This shows that the variation observed among the ethnic groups for the concentrations of certain endogenous VOCs is possibly due to the internal factors (such as, age, ethnicity, eating habits, social behavior, genetic make-up and body mass index), while the VOCs in breath, contributed from exogenous sources largely, remain similar or unchanged. More indepth investigations employing large and diverse sample groups are warranted to understand the contribution from various internal and external factors influencing the concentration of VOCs in exhaled breath within different ethnic groups.

Acetone (propylketone) was observed to be one of the most abundant organic compounds in human breath. Acetone is produced by hepatocytes via decarboxylation of excess Acetyl-CoA [31], and is oxidized via the Krebs cycle in peripheral tissues. Acetone concentrations are elevated when certain diseases and conditions such as diabetes mellitus occur [31]. Isoprene is another common VOC which is always present in human breath, and is thought to be formed along the mevalonic pathway of cholesterol synthesis [32]. The ratelimiting step in the cholesterol biosynthesis is the formation of mevalonate from acetic acid. 


\begin{tabular}{|l|l|l|l|l|l|l|l|l|}
\hline Subjects & Acetone & Isoprene & Acetonitrile & Ethanol & Acetaldehyde & Acrolein & Benzene & Toluene \\
\hline Chinese (5) & $350.5 \pm 22.7$ & $124.7 \pm 10.2$ & $2.9 \pm 1.5$ & $70 . \pm 8.8$ & $46.2 \pm 3.9$ & $4.3 \pm 0.1$ & $0.3 \pm 0.001$ & $0.7 \pm 0.1$ \\
\hline Indian (19) & $165.5 \pm 37.8^{*}$ & $121.2 \pm 41.8$ & $10.8 \pm 2.8^{*}$ & $95 . \pm 15.7$ & $39.6 \pm 3.6$ & $9.6 \pm 0.2^{*}$ & $0.4 \pm 0.001$ & $0.5 \pm 0.1$ \\
\hline Malaysian (5) & $256.8 \pm \pm$ & $125.5 \pm 23.5$ & $4.6 \pm 1.7^{*} \#$ & $75 \pm 4.3$ & $40.6 \pm 4.2$ & $5.7 \pm 1.1 \#$ & $0.5 \pm 0.002$ & $0.4 \pm 0.1$ \\
& $23.5^{*} \#$ & & & & & & & \\
\hline Singaporean (5) & $324.6 \pm 27.7 \#$ & $128.8 \pm 13.5$ & $2.4 \pm 1.9^{*}$ & $78 \pm 5.5$ & $42.4 \pm 3.9$ & $3.5 \pm 1.2 \#$ & $0.2 \pm 0.001$ & $0.3 \pm 0.1$ \\
\hline *p<0.05 with respect to Chinese volunteers; \#p<0.05 with respect to Indian volunteers (one way ANOVA with Newman-Keuls multiple post hoc test). \\
\hline
\end{tabular}

Table 4: Concentrations of VOCs (ppb) among different Asian population groups (Mean \pm S.D.)

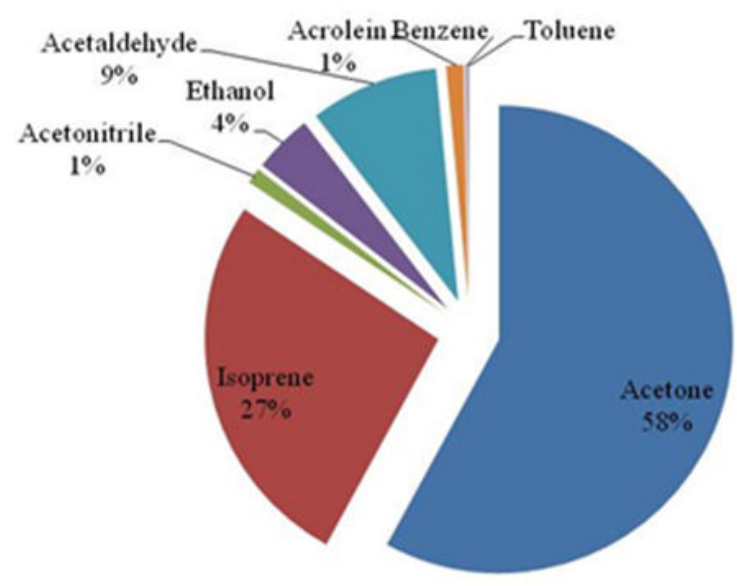

Figure 1: Relative abundance of selected VOCs in breath samples $(\%)$

Mevalonate is converted in the cytosol to isopentenyl pyrophosphate, which undergoes rapid isomerisation [33]. The isomerization product is then converted to isoprene via an acidcatalyzed elimination reaction [33]. Research studies also suggest that exhalation of isoprene may be related to oxidative damage to the fluid lining of the lung and the body [34]. The potential source of endogenous ethanol is the intestinal bacterial flora [35]. Acetaldehyde is produced by oxidation of endogenous ethanol, or locally in upper airway or mouth [36]. Acetonitrile, benzene and toluene are VOCs that result from exogenous sources and origins such as cigarette smoke, paints, solvents etc. These are widely present in indoor environments in developing as well as developed nations $[37,38]$.

In the present study, it was observed that concentrations of VOCs of endogenous origins (especially, acetone and acetaldehyde) as well as that of ethanol were different among various ethnic groups under study. Possible reasons for the observed differences could be the narrow age group, ethnicity, eating habits, social behavior, genetic make-up and body mass index [39]. A study reported by Turner et al. found high inter-individual variations in breath concentrations of acetone with mean values ranging from 148 to $2744 \mathrm{ppb}$ (Caucasian volunteers) [40] . Wang et al., also reported similar intra and inter individual variations in breath acetone concentrations (a mean value of $636 \mathrm{ppb}$; three volunteers monitored over a period of 30 days) [41]. These variations in acetone concentrations are not unusual as breath acetone is entirely systemic in origin [42]. In the present study, acetone concentration in breath samples of Indian subjects (165.5 ppb) was found to be the lowest among all the ethnic groups. Interestingly, acetone concentrations in breath samples of Chinese $(350.5 \mathrm{ppb})$ and Singaporean subjects (324.6 ppb) were observed to be quite similar. Since breath acetone is produced mainly from the spontaneous decarboxylation of acetoacetate, large variations in the breath acetone concentrations are often observed [42]. Due to its systemic origin, its concentrations in breath would be largely governed by internal factors which would vary in different ethnic population groups $[42,43]$. Previous research has shown that factors such as age, activity levels and diet are the possible reasons for variations observed in breath acetone concentrations $[42,43]$. In the present study, ethnicity of volunteers is likely to lead to differences in dietary patterns and activity levels (in terms of physical and social activities), thus possibly contributing to the differences in their breath acetone concentrations. However, to understand the role of ethnicity in influencing the breath concentrations of VOCs, thorough investigations using a large representative sample size are warranted.

Similar inter and intra-individual variations were also observed for isoprene, which is another endogenous VOC that is suggested to be involved in cholesterol metabolism [33]. Kushch et al. reported breath isoprene concentrations ranging from 5.8 to $274.9 \mathrm{ppb}$ for a mixed (male and female) cohort of 205 healthy volunteers [44]. Another study by Hornuss et al. reported mean concentrations of 14-174 ppb of breath isoprene in 16 healthy volunteers [45]. In the current study, isoprene concentrations ranged from 121.2-128.8 ppb which is within the range of concentrations reported in published studies. A wide range of ethanol and acetaldehyde concentrations have also been reported in the literature for healthy volunteers (43-1091 ppb for breath ethanol and 14-37 ppb for breath acetaldehyde); acetaldehyde has been involved in ethanol metabolism [46]. Concentrations for ethanol (70-95 ppb) observed in our study were within the concentration ranges as reported in literature [47]. Concentrations for acetaldehyde (39.6-46.2 ppb) observed in the present study are also similar to the concentrations observed in the literature reports. Literature reports are mainly based on breath examination of Caucasian populations [41,47], which could explain the differences observed in the breath concentrations of certain VOCs.

Apart from these VOCs, three exogenous VOCs (originating from occupational settings), namely, benzene, acrolein and toluene were also monitored in the present study. However, due to limited data available on the breath concentrations of VOCs originating from 
workplace and occupational settings, results from the present study cannot be compared against a reference point. Results for VOCs in exhaled breath have been mainly reported for Caucasian and American population groups. This pilot study aimed to understand the VOCs breath patterns for common (endogenous and exogenous) VOCs in Asian population groups. Some of the results obtained in this study are comparable to the data reported in the literature for Caucasian and other population groups.

Table S2 (Supplementary section) presents a compilation of the data reported in the literature for selected VOCs in breath samples of different population groups. However, owing to the ethnic, social, dietary and different workplace settings, more in-depth investigations are needed for Asian population groups to understand the VOCs patterns. Outcomes from the present study provide the scientific framework for future investigations in this area.

In view of the growing concern over increased exposure to air pollutants in Asian megacities, breath monitoring for Asian population groups assumes a central role in driving the risk assessment and management strategies. In this regard, PTRMS is a promising online analytical tool, which can be adopted for routine monitoring of VOCs in exhaled breath. Apart from workplace monitoring, PTR-MS could also be used in clinical settings for Asian population groups. The present study clearly demonstrates the capability and suitability of PTR-MS to monitor VOCs in real-time for diverse ethnic groups among Asian populations. PTR-MS results were further validated by conventional SPME-GCMS which further augments the credibility of this robust analytical technique for diverse Asian population groups.

\section{Conclusion}

This pilot study shows that BET-PTR-MS could be used as an online analytical method for workplace monitoring of VOCs among the Asian volunteers. Results indicate that PTR-MS has a high sensitivity and versatility (considering the diverse ethnic groups among Asian sub-continents) required for any breath monitoring tool for Asian population groups. Moreover, PTR-MS also eliminates the need for preconcentration of breath samples prior to measurements, making the estimations more reliable. Since Asian population groups are very diverse, the method of choice for VOC monitoring in exhaled breath should be able to measure VOCs concentrations with the least bias introduced by any means during either sampling, or chemical analysis of breath, apart from being robust and efficient. In this regard, PTRMS satisfies the requirements.

The present study represents a preliminary work on real-time analysis of exhaled breath using a non-invasive and fast diagnostic tool in Asian volunteers. The limitation of the present study is that only a small group of subjects were recruited. Hence, it is not possible to extrapolate the findings from this preliminary work to large cohorts and sample groups. More in-depth investigations with participation of a large number of Asian healthy volunteers would be needed to confirm the preliminary findings from this study.

\section{Competing Interests}

The authors confirm that they have no competing interests. We did not receive any fees or funding or have stocks or shares in organizations that may benefit from the publishing of this paper. We are not applying for patents related to the content of this manuscript. We do not have any non-financial competing interests.

\section{Acknowledgements}

Authors acknowledge and thank A-star BMRC-SERC grant (R-302-000-030-305) for the financial support extended to this project.

\section{References}

1. WHO (2007) Indoor Air pollution National burden of disease estimates. World Health Organization, Geneva, Switzerland.

2. UN (2009) United Nations Department of Economic and Social affairs/ Population Division. World Urbanization Prospects.

3. http://esa.un.org/unup/pdf/WUP2011_Highlights.pdf

4. http://dx.doi.org/10.1787/9789264183902-en

5. Langer S, Bekö G (2013) Indoor air quality in the Swedish housing stock and its dependence on building characteristics. Build Environ 69: 44-54.

6. Badjagbo K (2012) Potential of Breath Analysis: From Environmental Exposure Assessment to Medical Diagnosis. Webmed Central Environ Med 3.

7. Egeghy PP, Hauf-Cabalo L, Gibson R, Rappaport SM (2003) Benzene and naphthalene in air and breath as indicators of exposure to jet fuel. Occup Environ Med 60: 969-976.

8. Ghittori S, Alessio A, Negri S, Maestri L, Zadra P, et al. (2004) A field method for sampling toluene in end-exhaled air, as a biomarker of occupational exposure: correlation with other exposure indices. Ind Health 42: 226-234.

9. T Risby TH, Solga SF (2006) Current status of clinical breath analysis. ApplPhys 85: 421-426.

10. King J, Unterkofler K, Teschl G, Teschl S, Mochalski P, et al. (2012) A modeling-based evaluation of isothermal rebreathing for breath gas analyses of highly soluble volatile organic compounds. J Breath Res 6: 016005.

11. Vereb H, Dietrich AM, Alfeeli B, Agah M (2011) The possibilities will take your breath away: breath analysis for assessing environmental exposure. Environ SciTechnol 45: 8167-8175.

12. Alonso M, Sanchez JM (2013) Analytical challenges in breath analysis and its application to exposure monitoring. TrAC Trends Anal Chem 44: $78-89$.

13. Hansel A, A Jordan, R Holzinger, P Prazeller, W Vogel, et al. (1995) Proton transfer reaction mass spectrometry: on-line trace gas analysis at the ppb level. International Journal of Mass Spectrometry and Ion Processes 150: 609 - 619.

14. Blake RS, Monks PS, Ellis AM (2009) Proton-transfer reaction mass spectrometry. Chem Rev 109: 861-896.

15. Miekisch W, Schubert JK (2006) From highly sophisticated analytical techniques to life-saving diagnostics: Technical developments in breath analysis. Trends Anal Chem 25: 665-673.

16. Amann A, Smith D (2005) Breath Analysis for Clinical Diagnosis and Therapeutic Monitoring. World Scientific, Singapore.

17. King J, Kupferthaler A, Unterkofler K, Koc H, Teschl S, et al. (2009) Isoprene and acetone concentration profiles during exercise on an ergometer. J Breath Res 3: 027006.

18. King J, Kupferthaler A, Frauscher B, Hackner H, Unterkofler K, et al. (2012) Measurement of endogenous acetone and isoprene in exhaled breath during sleep. PhysiolMeas 33: 413-428.

19. Herbig J, Titzmann T, Beauchamp J, Kohl I, Hansel A (2008) Buffered end-tidal (BET) sampling-a novel method for real-time breath-gas analysis. J Breath Res 2: 037008.

20. Balasubramanian R, Qian WB, Decesari S, Facchini MC, Fuzzi S (2003) Comprehensive characterization of PM2.5 aerosols in Singapore. J Geophys Res 108: 4523.

21. Emmanuel SC (2000) Impact to lung health of haze from forest fires: the Singapore experience. Respirology 5: 175-182.

22. Beauchamp J, J Herbig, J Dunkl, W Singer, Hansel A (2013) On the performance of proton-transfer-reaction mass spectrometry for breathrelevant gas matrices. Measurement Science and Technology 24: 125003. 
23. Ligor T, Ligor M, Amann A, Ager C, Bachler M, et al. (2008) The analysis of healthy volunteers' exhaled breath by the use of solid-phase microextraction and GC-MS. J Breath Res 2: 046006

24. Song G, Qin T, Liu H, Xu GB, Pan YY, et al. (2010) Quantitative breath analysis of volatile organic compounds of lung cancer patients. Lung Cancer 67: 227-231.

25. Fenske JD, Paulson SE (1999) Human breath emissions of VOCs. J Air Waste ManagAssoc 49: 594-598.

26. Pauling L, Robinson AB, Teranishi R, Cary P (1971) Quantitative analysis of urine vapor and breath by gas-liquid partition chromatography. ProcNatlAcadSci U S A 68: 2374-2376.

27. Arthur CL, Pawliszyn J (1990) Solid phase microextraction with thermal desorption using fused silica optical fibers. Anal Chem 62: 2145-2148.

28. Ligor T, Szeliga J, Jackowski M, Buszewski B (2007) Preliminary study of volatile organic compounds from breath and stomach tissue by means of solid phase microextraction and gas chromatography-mass spectrometry. J Breath Res 1: 016001.

29. Phillips M, Herrera J, Krishnan S, Zain M, Greenberg J, et al. (1999) Variation in volatile organic compounds in the breath of normal humans. J Chromatogr B Biomed SciAppl 729: 75-88.

30. Miekisch W, Schubert JK, Noeldge-Schomburg GF (2004) Diagnostic potential of breath analysis--focus on volatile organic compounds. ClinChimActa 347: 25-39.

31. Lebovitz HE (1995) Diabetic ketoacidosis. Lancet 345: 767-772.

32. Stone BG, Besse TJ, Duane WC, Evans CD, DeMaster EG (1993) Effect of regulating cholesterol biosynthesis on breath isoprene excretion in men. Lipids 28: 705-708.

33. Deneris ES, Stein RA, Mead JF (1984) In vitro biosynthesis of isoprene from mevalonate utilizing a rat liver cytosolic fraction. BiochemBiophys Res Commun 123: 691-696.

34. Foster WM, Jiang L, Stetkiewicz PT, Risby TH (1996) Breath isoprene: temporal changes in respiratory output after exposure to ozone. J ApplPhysiol (1985) 80: 706-710.

35. Cope K, Risby T, Diehl AM (2000) Increased gastrointestinal ethanol production in obese mice: implications for fatty liver disease pathogenesis. Gastroenterology 119: 1340-1347.

36. Jones AW (1995) Measuring and reporting the concentration of acetaldehyde in human breath. Alcohol Alcohol 30: 271-285.

37. Wester RC, Maibach HI, Gruenke LD, Craig JC (1986) Benzene levels in ambient air and breath of smokers and nonsmokers in urban and pristine environments. J Toxicol Environ Health 18: 567-573.

38. Wallace L, Pellizzari E, Hartwell TD, Perritt R, Ziegenfus R (1987) Exposures to benzene and other volatile compounds from active and passive smoking. Arch Environ Health 42: 272-279.
39. Thekedar B, Szymczak W, Höllriegl V, Hoeschen C, Oeh U (2009) Investigations on the variability of breath gas sampling using PTR-MS. J Breath Res 3: 027007.

40. Turner C, Spanel P, Smith D (2006) A longitudinal study of ammonia, acetone and propanol in the exhaled breath of 30 subjects using selected ion flow tube mass spectrometry, SIFT-MS. PhysiolMeas 27: 321-337.

41. Wang T, Pysanenko A, Dryahina K, SpanÄ`l P, Smith D (2008) Analysis of breath, exhaled via the mouth and nose, and the air in the oral cavity. J Breath Res 2: 037013.

42. Spanel P, Dryahina K, Rejeskova A, Chippendale TW, Smith D (2011) Breath acetone concentration; biological variability and the influence of diet. PhysiolMeas 32: N23-31.

43. Spanel P, Dryahina K, Smith D (2007) Acetone, ammonia and hydrogen cyanide in exhaled breath of several volunteers aged 4-83 years. J Breath Res 1: 011001.

44. Kushch I, Arendacka B, Stolc S, Mochalski P, Filipiak W, et al. (2008) Breath isoprene - aspects of normal physiology related to age, gender and cholesterol profile as determined in a proton transfer reaction mass spectrometry study. ClinChem Lab Med 46: 1011-1018.

45. Hornuss C, Zagler A, Dolch ME, Wiepcke D, Praun S, et al. (2012) Breath isoprene concentrations in persons undergoing general anesthesia and in healthy volunteers. J Breath Res 6: 046004.

46. Freund G, O'Hollaren P (1965) Acetaldehyde concentrations in alveolar air following a standard dose of ethanol in man. J Lipid Res 6: 471-477.

47. Turner C, Spanel P, Smith D (2006) A longitudinal study of ethanol and acetaldehyde in the exhaled breath of healthy volunteers using selectedion flow-tube mass spectrometry. Rapid Commun Mass Spectrom 20: 61-68.

48. Stewart RD, Boettner EA (1964) EXPIRED-AIR ACETONE IN DIABETES MELLITUS. N Engl J Med 270: 1035-1038.

49. Stevens JF, Maier CS (2008) Acrolein: sources, metabolism, and biomolecular interactions relevant to human health and disease. MolNutr Food Res 52: 7-25.

50. Blomstrand R (1971) Observations of the formation of ethanol in the intestinal tract in man. Life Sci II 10: 575-582.

51. Lirk P, Bodrogi F, Deibl M, Kähler CM, Colvin J, et al. (2004) Quantification of recent smoking behaviour using proton transfer reaction-mass spectrometry (PTR-MS). Wien KlinWochenschr 116: 21-25.

52. Caldwell DJ, Armstrong TW, Barone NJ, Suder JA, Evans MJ (2000) Hydrocarbon solvent exposure data: compilation and analysis of the literature. AIHAJ 61: 881-894. 